\title{
Contractual Dimensions and Buyer-Supplier Perceived Risk: the Moderating Role of Information Technology Integration.
}

\author{
Yuting Wang \\ School of Management \\ University of Science and Technology of China \\ yutingw@mail.ustc.edu.cn \\ Hefu Liu \\ School of Management \\ University of Science and Technology of China \\ liuhf@ustc.edu.cn
}

\author{
Zhao Cai \\ Nottingham University Business School \\ University of Nottingham Ningbo China \\ zhao.cai@nottingham.edu.cn \\ Qian Huang \\ School of Management \\ University of Science and Technology of China \\ huangq@ustc.edu.cn
}

\begin{abstract}
The contract is widely conceived as an effective approach to decrease risk perception and resolve disputes. However, previous literature on the link between contracts and risk perception is contradictory, wherein both positive and negative findings exist. This study provides a novel insight about the mechanism of contractual dimensions and considers the boundary conditions of information technology (IT) integration. Data collected from 225 retailers of a manufacturer support most hypotheses. Specifically, contractual complexity has a positive influence on relational risk, and contractual recurrence has a negative influence on both performance and relational risk. This study further reveals the positive moderating effect of IT integration on the influence of contractual complexity on relational risk and the negative effect of IT integration on the influence of contractual recurrence on relational risk and performance risk. Implications and limitations of the study are discussed.
\end{abstract}

\section{Introduction}

The last decades witnessed the expansion of collaborative network where focal firms simultaneously interact with plenty of partners for external resources [1-3]. However, the fear of uncertainty about the economic and collaboration is inherent in these relationships [3]. Such concern of risk makes both parties discreet on engaging in relationships and ultimately impedes the creation of joint value $[4,5]$. Conceivably, it is pivotal for focal firms to decrease their counterparts'perceived risk regarding maintaining a relationship and achieving performance [5-8]. However, as scholars pointed out, "practices to manage inter-firm risks and enhance collaborative action have received much less research attention” [9, p. 2]. Accordingly, investigating how to reduce partners' risk perception not only solves the collaborative problem faced by focal firms but also bridges research gaps in risk management.

The contract is widely conceived as an effective approach to decrease risk perception and resolve disputes [10, 11]. Some contracts contain a large number of provisions which obviates moral hazards and attenuates the leeway for opportunism [8, 12, 13]. Others seek to codify as little as possible and focus heavily on ensuring that the parties have a shared understanding of the relationship so that they can coordinate partners optimally [14]. These mixed understanding impede the advancement of this line of research and manifest the necessity to identify how to reduce risk perception by contract design.

We find researchers suggest that parties are more stable when stress coordination mechanism than when contracts focus on safeguard mechanism [15-17]. Hence, we raise the coordination function of contract in the context of risk perception $[14,18]$. This study is an effort to address such theoretical gap by investigating how to reduce risk perception by designing contract for coordination.

Poppo and Zhou [19] refine contractual dimensions which include both safeguard and coordination mechanism. One dimension is contract complexity which considers many future contingencies that would change the value of performance-increases in the costs of their inputs, the decline in demand for the products, and so on [20]. The other dimension is contract recurrence which refers to whether parties rely on the expectation of continued exchanges to collaborate with their partners [19].

Inter-firm information technology (IT) artifacts play an increasingly crucial role in contract governance [21]. As Chi, Zhao [22] claimed, many firms use highly integrated IT artifacts to facilitate electronic data interchange. For example, Amazon.com provides an information system for hundreds of retailers to create value for its partners by providing information integration for searching, ordering, and communication to reduce conflict beyond contracts [23]. These highly integrated information systems provide a key platform to coordinate parties that enables them to acquire information and use it to interact effectively [24-26]. According to transaction cost economy (TCE) perspective, effective information flow supported by integrated IT artifacts aligns well to contracts for coping with hazards [27]. Specifically, IT integration brings behavioral transparency which improves awareness of both parties on how contracts are implemented.

Moreover, frequent and instant communications are 
facilitated by integrated IT artifacts, which is conducive to reaching a consensus of understanding contract clauses to guide their collaboration. The effectiveness of contract framing on reducing perceived risk is enhanced as a consequence. Although incorporating IT integration in the relationship between contract framing and risk perception is important; its moderating role has not been investigated so far. Therefore, our research is a trial to address this research gap by exploring how IT integration moderates the relationship between contract framing and risk perception.

These gaps form the basis of our conceptual model, which examines how contracts, risk perceptions, and IT integration are intertwined. We ask (1) How does the coordination mechanism of contract (i.e., contractual complexity and recurrence) differentially reduce risk perception (i.e., performance risk and relational risk)? (2) How does IT integration moderate the relationship between these contractual dimensions and risk perception?

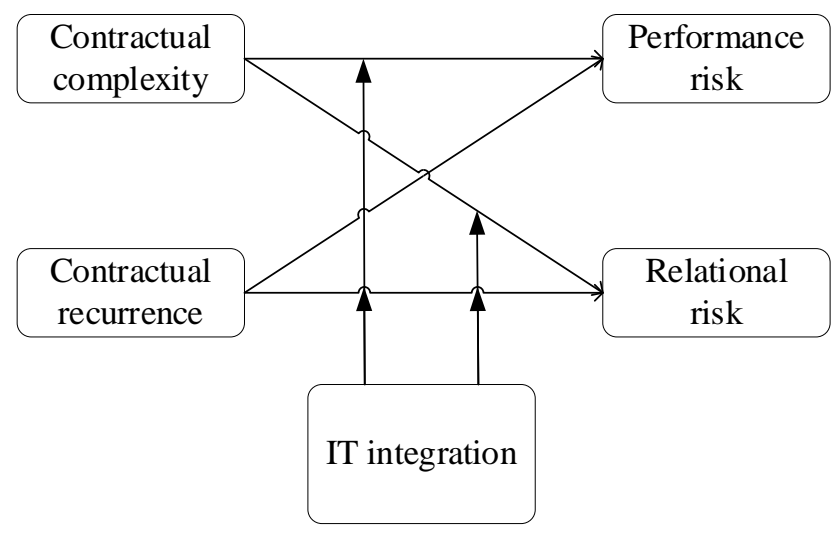

Figure1. Research model

\section{Conceptual development}

\subsection{Transaction Cost Economy}

Over the last twenty years, the standard framework for analyzing questions regarding the choice of organizational governance form has been transaction cost theory. TCE describes the firm as an efficiency-inducing administrative instrument that facilitates exchange between parties. Also, TCE emphasizes on the deeper and more cooperative responses that are available through conscious, deliberate, and purposeful coordination. According to TCE, it is costly to negotiate and write complete contingent claims contracts that fully describe each party's responsibilities and rights for all future contingencies [19]. Contract is hard to be complete. Also, some researchers point out the continuity of exchange is vital to its effectiveness based on TCE [27]. As such, this study builds on TCE as the theoretical underpinning to explain how the complexity of contract and the continuity of an exchange affect risk perception.

\subsection{Perceived risks}

Perceived risk is often defined as the probability of unfavorable outcomes, which is hard to be estimated [28]. There are two types of risk in perceived risk. One refers to the partner not cooperating in good faith (namely, relational risk), in addition to the usual risk of unsatisfactory business performance (called performance risk). In inter-organizational collaborative relationships, relational risk is defined as the probability and consequences of not having satisfactory cooperation [6]. This risk arises because of the potential for opportunistic behavior and conflicts on the part of both firms. Opportunistic behavior is in shirking, cheating, distorting information, appropriating resources, and so on. Conflicts arise because firms have their interests that are not necessarily congruent with those of their partners [28]. Besides relational risk, many other factors may adversely affect performance. These factors include intensified rivalry, new entrants, demand fluctuations, changing government policies, a lack of competence of the partner firms, and sheer bad luck. These factors account for performance risk, or the probability and consequences that objectives are not achieved, despite satisfactory cooperation among partner firms [6]. 
The improvement of perceived risk can help to maintain a relationship and achieve performance [5]. Control is widely acknowledged as essential in inter-organizational relationships to reduce perceived risk $[5,6]$. Contract is an important part of control governance in an inter-organizational relationship [29]. Hence, we take contracts into consideration, which helps to understand how to decrease the perceived risk.

\subsection{Contracts}

Researchers framed contracts into contingency-based complexity and incentive-based recurrence [19]. Contractual complexity is the flexibility of contract and takes "account of many future contingencies that would change the value of performance-increases in the costs of inputs, the decline in demand for the product, and so on" [20]. When change forces two parties to adapt or modify an initial agreement, a contract which accounts of many future contingencies offers guidelines to avoid an inequitable state [30]. Contractual recurrence is the continuity of contract and refers to whether parties rely on the expectation of continued exchanges to collaborate with their partners [19]. Partners with the expectation of long collaboration want to have a stable, reciprocal strategy in the further. Researchers highlight the coordinating frame of contracting can motivate parties to cooperate [19]. As such, this study builds on TCE as the theoretical underpinning to explain how the coordinating of contract affects risks.

\subsection{Contracts and perceived risk}

Complex contracts usually include many contingency clauses, which provide a more comprehensive solution and makes the adaptive adjustments in a changeable environment. When parties articulate many contingencies in their contracts, they seek to accommodate the transaction to a variety of states or future possibilities, thereby easing conflict and disputes of performance. Under these situations, they will promote efficiency and produce the positive performance outcome and reduce performance risk.

When the contract includes too many specific contingencies clauses, partners may be cannot follow all the details of the contract. Once they do not finish the rules or do something little inconsistent with the contract, such behavior may be claimed as the destruction of the rule and easily break the friendship between them, turning a collaborator into an antagonist.

Contract recurrence indicates that partners have expectations of which extend beyond the duration of the current contract and stress the long-term contractual partnerships [16]. Partners are willing to fulfill the performance agreement because they believe they will be rewarded through repeat business [31]. As Poppo, Zhou [32] demonstrated, because both of them have the shared intent to honor the performance agreement, the recurrent exchanges can realize higher performance.

When exchange parties hold a long-term view of the exchange, they are motivated to cooperate [33]. Such incentive alignment associated with greater expectations of continued exchange can promote collaborative relationship [32]. If parties expect to transact with one another, they will 'try to resolve any' conflicts [32]. According to SET, to get more benefits in the future, the reciprocal behavior will reduce the uncertainty and risks. Thus, if the focal firm place sufficient value on continued transactions, they will keep a good relationship with the parties.

\section{Hypotheses development Moderating roles of information integration}

With the development of information integration, for performance risk with complex contracts, partners can get enough communications, and they will know each other deeply. If they have something confused, they can easily find relevant information because of the highly integrated information system. According to transaction cost economy (TCE) perspective, effective information flow supported by integrated IT artifacts aligns well to contracts for coping with hazards. Also, highly integrated information can increase their task efficiency and decrease the Jumbled procedure to get what you want as soon as possible. Frequent and instant communications are facilitated by integrated IT technology, which is conducive to reaching a consensus of understanding contract clauses to guide their collaboration.

However, for relational risk with complex contracts, contract with so many contingencies have already threatened the harmony relationship. In such a situation, Partners may feel be monitored on the collaboration. It may take deep this harmful relationship if the IT integration is still very high. Hence, we propose the following.

H1: IT integration positively moderates the effect of contractual complexity on performance risk.

H2: IT integration positively moderates the effect of contractual complexity on relational risk.

Contract recurrence is a symbol of continuous collaboration, which means that both parties know each other well. If they have perceived high contract recurrence, they will rely more on the expectation of continued exchanges to coordinate and safeguard 
transactions instead of information flows online. A lot of roles have been established by usage, and they need to follow the routine. So we propose the following.

H3: IT integration negatively moderates the effect of contractual recurrence on performance risk.

H4: IT integration negatively moderates the effect of contractual recurrence on relational risk.

\section{Methodology}

\subsection{Data collection}

To test above hypotheses, we collaborated with a large water heater manufacturer in China called Company C. China is an ideal research setting, typifying an emerging market because of its population, fast growing economy, increased liberalization of most economic sectors and its role as a global manufacturing center. China has become an indispensable part of the global supply chain. This study collected 428 survey questionnaires from the retailers of Company $\mathrm{C}$. Finally, 225 valid questionnaires were collected with a response rate of approximately 53\%. Following Armstrong and Overton [34], we tested for potential non-response bias. We compare the chi-squares of the key measures of the responses from the first $25 \%$ of the respondents and those of the final $25 \%$. We did not observe significant differences between the two groups on these items. This result indicated that non-response bias was not serious in this study. The demographic information is shown in Table 1.

Table 1. Demographic information

\begin{tabular}{llc}
\hline & Frequency & Percent (\%) \\
\hline Number of employees & & \\
Less than 10 & 23 & 10.222 \\
10-50 & 87 & 38.667 \\
51-100 & 48 & 21.333 \\
More than 100 & 67 & 29.778 \\
Firm age & & \\
Less than 4 years & 35 & 15.556 \\
4-6 & 52 & 23.110 \\
7-10 & 69 & 30.667 \\
More than 10 & 69 & 30.667 \\
Number of IT employees & & \\
Less than 2 & 135 & 60.000 \\
2-4 & 84 & 37.333 \\
More than 4 & 6 & 2.667 \\
\hline
\end{tabular}

\subsection{Measurement}

An English questionnaire was first developed according to previously validated measures from the existing literature. We hired a translator who was unfamiliar to this research to translate the questionnaire into Chinese. The translated questionnaire was sent to both scholars and practitioners to check for readability and accuracy. After being revised regarding some items, the Chinese version was translated back to English by another professional translator. Finally, we carefully compared the back-translated questionnaire with the original one and determined no significant semantic difference between both versions. Thus, the questionnaire in Chinese is equivalent to that in
English.

All items were measured on five-point Likert scales, which ranged from "strongly agree" to "strongly disagree." The measurement items for the dependent variable, namely, relational risk, were adapted from Liu [35]. Relational risk (RSK) arising from firm-firm interaction, whereas performance risk (PSK) from the firm-environment interaction.

We used scales from Poppo and Zhou [19] to measure the buyer-supplier contract, namely, contract complexity (CC) and contract recurrence (CR). We measured IT integration [25]. We used three items adapted from Rai and Tang [25]. IT integration refers 
to the ability of a firm to integrate data, communication technologies, and transaction and collaboration applications with its IR portfolio.

We also considered firm size (SIZE), firm age (AGE), the number of IT staff (ITD), justice and relationship length (Length) as control variables, which may influence the perceived risk of buyer firms. For example, firms with large IT departments feature sufficient human capital in reducing risks [36]. A large number of IT staff also indicates high IT capability, which helps the firm manage the relationship with suppliers in the future [24]. Thus, the number of IT staff may negatively affect perceived risk.

\section{Data analysis}

We initially checked the possible common method bias caused by perceptual data, which were collected from a single source at one point in time, common method bias was tested as follows. Then, we adopted Harman's one-factor test. With eigenvalues greater than 1.0 and account for $69.16 \%$ of the variance. The first component did not account for the majority of the variance (34.76\%). All method factor loadings are insignificant as well. The results of the tests ensure that common method bias is unlikely to be an issue in the study. Thus, common method bias was not a grave concern in this study according to Harman's one-factor test.

\subsection{Common method bias}

This study employed SPSS19.0 to evaluate the validity and reliability of the measurement model. In Table 2, loadings of all items are above the criterion of 0.6 and scores of for AVEs of all constructs are greater than the benchmark value of 0.50. Estimates of Cronbach's Alpha and composite reliability are higher than the benchmark value of 0.70 . These results indicate that a favorable convergent validity and reliability of the measurement model of this study. We assessed discriminate validity following the method suggested by Paulraj, Lado [37], in which the correlation between two constructs and the corresponding AVE score were compared. Table 3 shows that the correlations among constructs were lower than the corresponding square root of AVE score. The result suggested the good discriminate validity of this dataset.

Table 2. Cronbach's alpha, composite reliability, AVE, and loading of indication variables.

\begin{tabular}{|c|c|c|c|c|c|}
\hline & Items & Loading & Cronbach's & Composite & AVE \\
\hline & & & alpha & reliability & \\
\hline $\mathrm{CC}$ & 4 & $0.903 \sim 0.915$ & 0.929 & 0.949 & 0.824 \\
\hline CR & 3 & $0.843 \sim 0.910$ & 0.853 & 0.911 & 0.773 \\
\hline RSK & 3 & $0.788 \sim 0.883$ & 0.805 & 0.886 & 0.721 \\
\hline PSK & 3 & $0.936 \sim 0.959$ & 0.941 & 0.962 & 0.895 \\
\hline ITI & 4 & $0.822 \sim 0.894$ & 0.879 & 0.917 & 0.734 \\
\hline
\end{tabular}

Table 3. Means, standard deviations, and correlations

\begin{tabular}{|c|c|c|c|c|c|c|c|c|c|c|c|}
\hline & Means & SD & 1 & 2 & 3 & 4 & 6 & 7 & 8 & 9 & 10 \\
\hline$\infty$ & 3.700 & 0.682 & 0.908 & & & & & & & & \\
\hline CR & 3370 & 0.426 & $03724+$ & 0.879 & & & & & & & \\
\hline RSK & 3.200 & 0922 & 0.086 & $0.192^{*+}$ & 0.849 & & & & & & \\
\hline PSK & 3330 & 0.884 & $0.216^{44}$ & $-0.149^{4}$ & $0.6084+$ & 0.946 & & & & & \\
\hline ITI & 3.526 & 0.843 & $0.444^{\circ *}$ & $0.283^{* \bullet}$ & -0.096 & -0.034 & 0.857 & & & & \\
\hline SIZE & $\mathbf{N} . \mathbf{A}$ & N.A. & $0.106^{*}$ & $0.111^{*}$ & 0.068 & $0.119^{*}$ & 0.017 & N.A. & & & \\
\hline AGE & $\mathbf{N} . \mathbf{A}$ & N.A. & $.0 .052^{*}$ & 0.086 & 0.035 & 0.079 & 0.026 & $0.182^{* *}$ & N.A. & & \\
\hline ITD & N.A. & N.A. & 0.006 & 0.072 & 0.024 & -0.095 & 0.022 & $0.439 * *$ & $0.311 \%$ & N.A. & \\
\hline Justice & $\mathbf{N} . \mathbf{A}$ & N.A. & $0338^{4 *}$ & $0.247 * 4$ & $0.165^{*}$ & $0.271^{* 4}$ & $0.268 * *$ & 0.074 & 0.019 & 0.041 & N.A. \\
\hline Length & N.A. & N.A. & 0.039 & 0.045 & 0.057 & 0.050 & 0.003 & $0210^{4+4}$ & $0.26 \mathrm{~T}^{4+4}$ & 0.045 & $0.167^{*}$ \\
\hline
\end{tabular}

Note: The diagonal elements are the square roots of AVEs; ${ }^{*} \mathrm{p}<0.05$; ${ }^{* *} \mathrm{p}<0.01 ;{ }^{* * *} \mathrm{p}<0.001$ 


\subsection{Hypotheses testing}

Hierarchical regression analysis is conducted to test the hypotheses. We standardize the variables to minimize the possibility of multicollinearity [38]. As shown in Model 1 of Table 4, justice significantly has related to relational and performance risk. Model 2 is a model that contained independent variables. Model 3 adds moderators. Model 4 includes all the variables. The results showed that most of the hypotheses were supported, except Hypothesis $4(\beta=-0.139, \mathrm{p}>0.01)$. IT capability $\times$ contractual complexity relates negatively to performance risk $(\beta=0.180, \mathrm{p}<0.001)$, in support of Hypothesis 1 . IT integration $\times$ contractual complexity relates positively to relational risk $(\beta=$ 0.258 , $\mathrm{p}<0.05$ ), in support of Hypothesis 2. IT capability $\times$ contractual recurrence relates negatively to performance risk $(\beta=-0.195, \mathrm{p}<0.01)$, in support of Hypothesis 3.

To further analyze the moderating effects, we follow the graphical procedure suggested by Aiken, West [38] to draw Figs. 2, 3 and 4.

Table 4. Results of hierarchical regression analysis

\begin{tabular}{|c|c|c|c|c|c|c|c|c|}
\hline & \multicolumn{4}{|c|}{ Relational risk } & \multicolumn{4}{|c|}{ Performancerisk } \\
\hline & $1^{\text {Model }}$ & Model 2 & Model 3 & Model 4 & Model 1 & Model 2 & Model 3 & Model 4 \\
\hline Length & 0.035 & 0.036 & 0.034 & 0.039 & 0.020 & -0.006 & -0.008 & -0.008 \\
\hline Justice & $0.151^{*}$ & $0.185^{*}$ & $0.204^{\mu \cdots}$ & $0.231^{*}$ & $0.269^{\cdots}$ & $0.267^{\prime \cdots}$ & $0.286^{\cdots \cdots}$ & $0.314^{\cdots \cdots}$ \\
\hline SIZZ & -0.112 & -0.054 & -0.058 & -0.022 & -0.106 & -0.036 & -0.040 & -0.009 \\
\hline$A G E$ & 0.094 & 0.103 & 0.101 & 0.074 & -0.001 & 0.010 & 0.009 & -0.015 \\
\hline ITD & 0.038 & 0.029 & 0.032 & 0.014 & -0.061 & -0.075 & -0.071 & -0.085 \\
\hline $\mathrm{cC}$ & & $0.132^{+}$ & $0.188^{*}$ & $0.258^{* 4}$ & & $0.231^{*}$ & $0.289^{\cdots \cdots}$ & $0.344^{\cdots \cdots}$ \\
\hline CR & & $-0.288^{*}$ & $-0.268^{* 4}$ & $-0.351^{*}$ & & $-0.292^{40 *}$ & $-0.272^{* * *}$ & $-0.367^{* * *}$ \\
\hline ITI & & & $-0.159^{*}$ & $-0.141^{\cdots}$ & & & $-0.162^{*}$ & $-0.133^{+}$ \\
\hline $\operatorname{mr} x$ & & & & $0.258^{*}$ & & & & $0.180^{\cdots \cdots}$ \\
\hline CC & & & & & & & & \\
\hline $\operatorname{IT} \times$ & & & & -0.139 & & & & $-0.195^{\prime \prime}$ \\
\hline CR & & & & & & & & \\
\hline $\mathbf{F}$ & 1.816 & $8.406^{\cdots}$ & $4.905^{*}$ & $7.957^{* *}$ & $4.599^{* *}$ & $11.238^{+* *}$ & $5.541^{\circ}$ & $5.953^{* *}$ \\
\hline $\mathbf{R}^{2}$ & 0.039 & 0.107 & 0.127 & 0.183 & 0.093 & 0.177 & 0.197 & 0.239 \\
\hline$\triangle \mathrm{R} 2$ & 0.039 & 0.068 & 0.019 & 0.057 & 0.073 & 0.151 & 0.168 & 0.204 \\
\hline
\end{tabular}

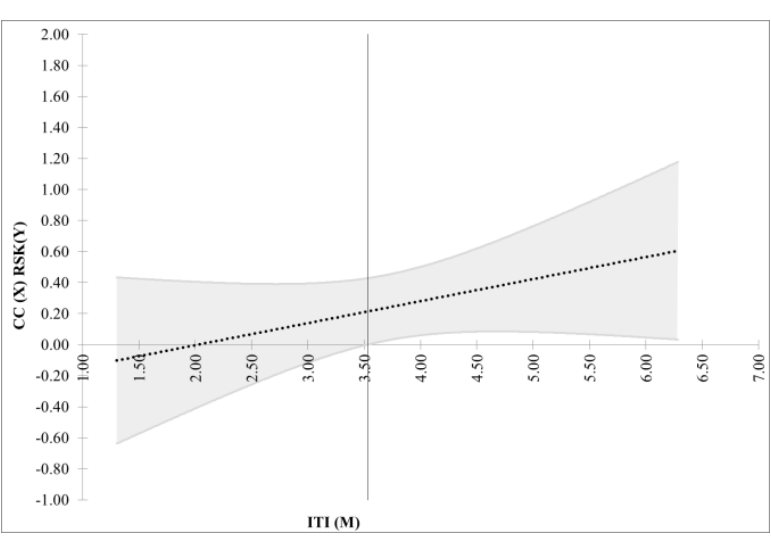

Figure 2. Moderating effect of information integration on relationship between contract complexity and relational risk 


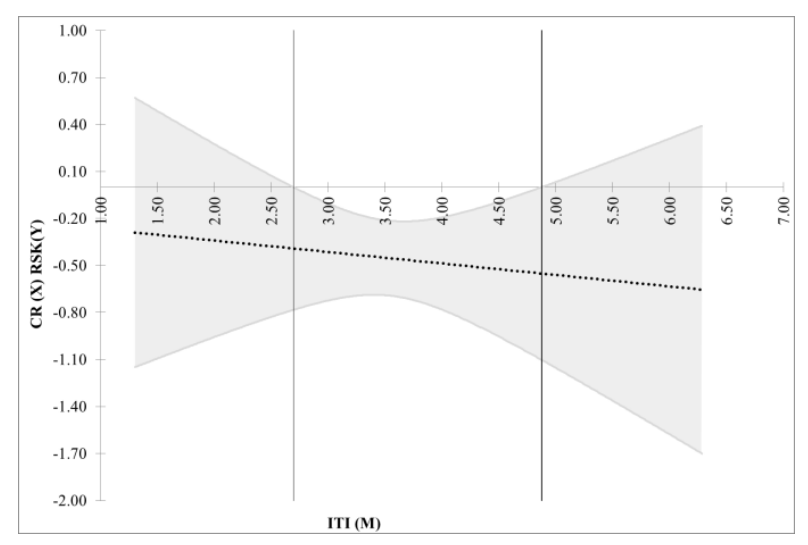

Figure 3. Moderating effect of information integration on relationship between contract recurrence and relational risk

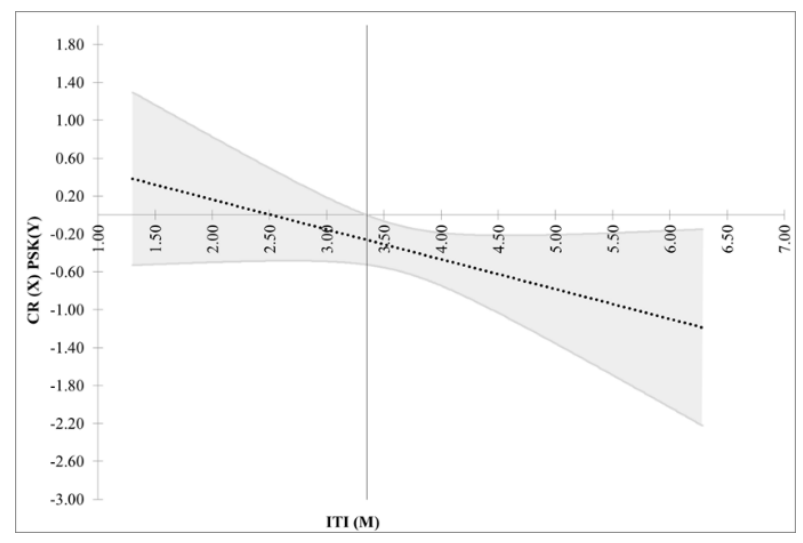

Figure 4. Moderating effect of information integration on relationship between contract recurrence and performance risk

\section{Discussion}

We established a theoretical context to investigate the proposition that contractual dimensions can decrease risk perception in the Chinese context. The findings support the basic premise of TCE that contract governance plays a crucial role in inter-organizational relationship. This study reveals the positive moderating effect of IT integration on the influence of contractual complexity on relational risk and the negative effect of IT integration on the influence of contractual recurrence on relational risk and performance risk.

The results of this study do not support the hypothesis of the association between contractual complexity and performance risk. Based on TCE, the adaptive environment is more prone to opportunism due to bounded rationality [21]. Thus, the performance risk cannot be improved when the contract is complexity.

\section{Implications and limitations}

\subsection{Practical implications}

The findings of this study also offer managerial implications for suppliers in designing contract. When drafting complex clauses, lawyers should avoid stressing the basis of conflict and change. It takes time to learn how to craft better contracts; managers may pay attention to some important contingencies they do not need to cover all of them. Managers should adopt appropriate procedures to result in fewer risk perceptions.

Our results also suggest that when drafting complex clauses, managers should think more carefully to integrate the information, which may be seen as a kind of electronic surveillance. Under such situation, contractual complexity fosters greater risk perceptions.

Further, contractual recurrence can efficiently incentivize cooperation by setting expectations that "you expect to be working together for a long time." 
Our findings suggest managers must give a deep understand of recurrent transactions. Such procedure will weaken risk perception if managers frequently integrate their information. From our findings, managers can attempt to integrate with its buyers, emphasizing that our contracts are not complex and our purpose is to build a long-term relationship with our partners.

\subsection{Limitations and future research}

Evaluating the contributions of this study in light of certain limitations is necessary. First, we highlight the boundary role of information integration in effect on contract and perceived risk. However, considering other IT factors is also very important. Future research can consider other relevant factors that were investigated in inter-organizational relationships, such as absorbing ability and information sharing to enrich the current understanding of the relationship between contract and perceived risk. Second, all key constructs in this study were measured by the perceptions of individual respondents, which are subjective. Although our analysis results prove that the common method bias is not a serious problem, future researchers must use objective data or collect data from multiple informants. Third, the generalizability of our findings may be limited by the demography of respondents because we only measured the retailers of one manufacturer. Doing so may enhance the internal validity of this study but may limit its external validity. Therefore, scholars and practitioners should exercise caution in generalizing our findings to a company located in different economic, political, and cultural environments.

\section{Reference}

[1] Parmigiani, A. and M. Rivera-Santos, Clearing a path through the forest: A meta-review of interorganizational relationships. Journal of Management, 2011. 37(4): p. 1108-1136.

[2] Dekker, H.C., Control of inter-organizational relationships: evidence on appropriation concerns and coordination requirements. Accounting, Organizations and Society, 2004. 29(1): p. 27-49.

[3] Lunnan, R. and S.A. Haugland, Predicting and measuring alliance performance: A multidimensional analysis. Strategic Management Journal, 2008. 29(5): p. 545-556.

[4] Langfield-Smith, K., The relations between transactional characteristics, trust and risk in the start-up phase of a collaborative alliance. Management Accounting Research, 2008. 19(4): p. 344-364.

[5] Ding, R., H.C. Dekker, and T. Groot, Risk, partner selection and contractual control in interfirm relationships. Management Accounting Research, 2013. 24(2): p. 140-155. [6] Das, T. and B.-S. Teng, The risk-based view of trust: A conceptual framework. journal of Business and Psychology,
2004. 19(1): p. 85-116.

[7] Ribbink, D. and C.M. Grimm, The impact of cultural differences on buyer-supplier negotiations: An experimental study. Journal of Operations Management, 2014. 32(3): p. 114-126.

[8] Mesquita, L.F. and T.H. Brush, Untangling safeguard and production coordination effects in long-term buyer-supplier relationships. Academy of Management Journal, 2008. 51(4): p. 785-807.

[9] Dekker, H.C., J. Sakaguchi, and T. Kawai, Beyond the contract: Managing risk in supply chain relations. Management Accounting Research, 2013. 24(2): p. 122-139. [10] Schepker, D.J., et al., The many futures of contracts: Moving beyond structure and safeguarding to coordination and adaptation. Journal of Management, 2014. 40(1): p. 193-225.

[11] Malhotra, D. and F. Lumineau, Trust and collaboration in the aftermath of conflict: The effects of contract structure. Academy of Management Journal, 2011. 54(5): p. 981-998.

[12] Argyres, N. and K.J. Mayer, Contract design as a firm capability: An integration of learning and transaction cost perspectives. Academy of Management Review, 2007. 32(4): p. 1060-1077.

[13] Kalkanci, B., K.-Y. Chen, and F. Erhun, Contract complexity and performance under asymmetric demand information: An experimental evaluation. Management science, 2011. 57(4): p. 689-704.

[14] Lumineau, F. and D. Malhotra, Shadow of the contract: How contract structure shapes interfirm dispute resolution. Strategic Management Journal, 2011. 32(5): p. 532-555.

[15] Duan, M., The role of formal contracts with weak legal enforcement: A study in the Chinese context. Strategic Organization, 2012. 10(2): p. 158-186.

[16] Weber, L. and K.J. Mayer, Designing effective contracts: Exploring the influence of framing and expectations. Academy of Management Review, 2011. 36(1): p. 53-75.

[17] Weber, L., K.J. Mayer, and J.T. Macher, An analysis of extendibility and early termination provisions: The importance of framing duration safeguards. Academy of Management Journal, 2011. 54(1): p. 182-202.

[18] Mayer, K.J. and N.S. Argyres, Learning to contract: Evidence from the personal computer industry. Organization Science, 2004. 15(4): p. 394-410.

[19] Poppo, L. and K.Z. Zhou, Managing contracts for fairness in buyer-supplier exchanges. Strategic Management Journal, 2014. 35(10): p. 1508-1527.

[20] Eggleston, K., E.A. Posner, and R. Zeckhauser, The design and interpretation of contracts: why complexity matters. Nw. UL Rev., 2000. 95: p. 91.

[21] Lumineau, F. and J.E. Henderson, The influence of relational experience and contractual governance on the negotiation strategy in buyer-supplier disputes. Journal of Operations Management, 2012. 30(5): p. 382-395.

[22] Chi, M., et al., The influence of inter-firm IT governance strategies on relational performance: The moderation effect of information technology ambidexterity. International Journal of Information Management, 2017. 37(2): p. 43-53.

[23] Grover, V. and R. Kohli, Cocreating IT value: new capabilities and metrics for multifirm environments. Mis Quarterly, 2012: p. 225-232. 
[24] Li, M., X. Zheng, and G. Zhuang, Information technology-enabled interactions, mutual monitoring, and supplier-buyer cooperation: A network perspective. Journal of Business Research, 2017.

[25] Rai, A. and X. Tang, Leveraging IT capabilities and competitive process capabilities for the management of interorganizational relationship portfolios. Information Systems Research, 2010. 21(3): p. 516-542.

[26] Wade, M. and J. Hulland, The resource-based view and information systems research: Review, extension, and suggestions for future research. MIS quarterly, 2004. 28(1): p. 107-142.

[27] Poppo, L. and T. Zenger, Do formal contracts and relational governance function as substitutes or complements? Strategic management journal, 2002. 23(8): p. 707-725.

[28] Das, T.K. and B.-S. Teng, Trust, control, and risk in strategic alliances: An integrated framework. Organization studies, 2001. 22(2): p. 251-283.

[29] Das, T. and B.-S. Teng, A risk perception model of alliance structuring. Journal of International Management, 2001. 7(1): p. 1-29.

[30] Ariño, A. and J.J. Reuer, Designing and renegotiating strategic alliance contracts. The Academy of Management Executive, 2004. 18(3): p. 37-48.

[31] Griffith, D.A., M.G. Harvey, and R.F. Lusch, Social exchange in supply chain relationships: The resulting benefits of procedural and distributive justice. Journal of operations management, 2006. 24(2): p. 85-98.

[32] Poppo, L., K.Z. Zhou, and S. Ryu, Alternative origins to interorganizational trust: An interdependence perspective on the shadow of the past and the shadow of the future. Organization Science, 2008. 19(1): p. 39-55.

[33] Tanskanen, K., Who wins in a complex buyer-supplier relationship? A social exchange theory based dyadic study. International Journal of Operations \& Production Management, 2015. 35(4): p. 577-603.

[34] Armstrong, J.S. and T.S. Overton, Estimating nonresponse bias in mail surveys. Journal of marketing research, 1977: p. 396-402.

[35] Liu Y, Li Y, Tao L, et al. Relationship stability, trust and relational risk in marketing channels: Evidence from China[J]. Industrial Marketing Management, 2008, 37(4): 432-446.

[36] Bloom, N., et al., The distinct effects of information technology and communication technology on firm organization. Management Science, 2014. 60(12): p. 2859-2885.

[37] Paulraj, A., A.A. Lado, and I.J. Chen, Inter-organizational communication as a relational competency: Antecedents and performance outcomes in collaborative buyer-supplier relationships. Journal of operations management, 2008. 26(1): p. 45-64.

[38] Aiken, L.S., S.G. West, and R.R. Reno, Multiple regression: Testing and interpreting interactions. 1991: Sage. 